Supporting Information

\title{
Fabrication of perovskite solar cells with digital control of transparency by inkjet printing
}

\author{
Pendyala Naresh Kumar, Shlomo Magdassi*, Lioz Etgar* \\ *e-mail lioz.etgar@mail.huji.ac.il, magdassi@mail.huji.ac.il
}

The Hebrew University of Jerusalem, Institute of Chemistry, Casali Center for Applied Chemistry, Jerusalem 91904, Israel
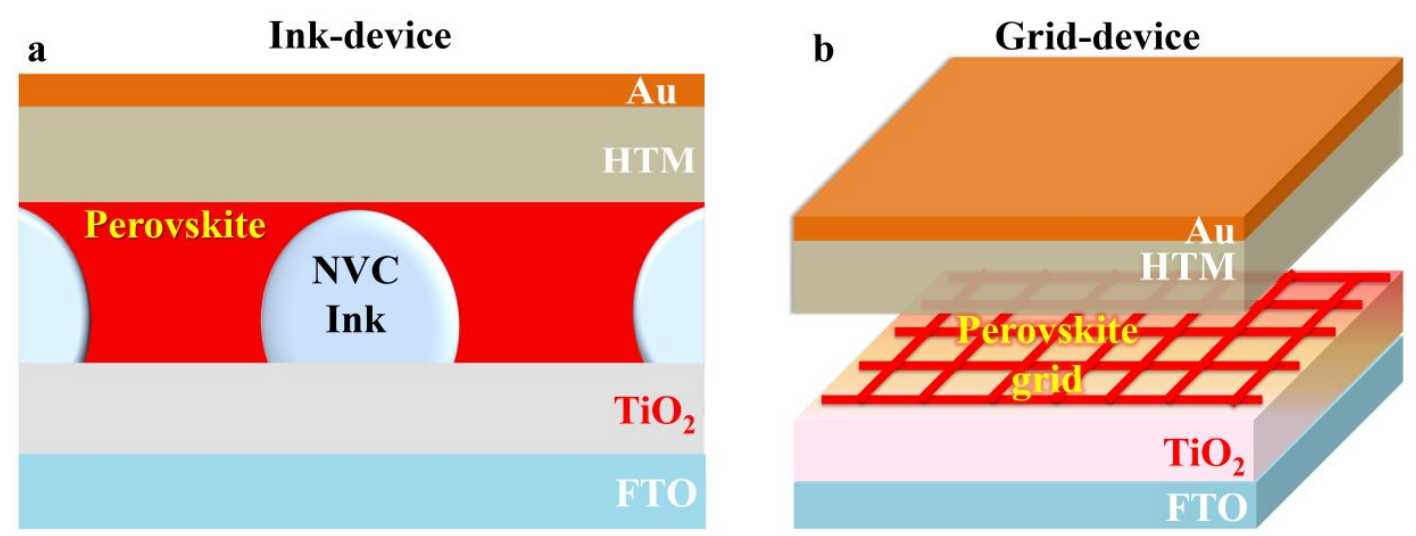

Figure S1: The schematic illustrates the cross-sectional view of NVC ink-device (a); and 3dimensional view of the perovskite grid-device (b). 
Table S1: The average PCE parameters obtained for twenty solar cells and for the champion device with the configuration $\mathrm{FTO} / \mathrm{TiO}_{2} / \mathrm{NVC}$-ink/Perovskite/HTM/Au (active area is 0.088 $\mathrm{cm}^{2}$ ), under 1 Sun illumination.

\begin{tabular}{lllll}
\hline \hline $\mathrm{V}_{\mathrm{OC}}(\mathrm{V})$ & $\mathrm{J}_{\mathrm{SC}}\left(\mathrm{mAcm}^{-2}\right)$ & $\mathrm{FF}(\%)$ & $\mathrm{PCE}(\%)$ & AVT (\%) \\
\hline $1.02+/-0.06$ & $15.4+/-1.05$ & $65.1+/-7.3$ & $10.2+/-1.0$ & $23+/-2$ \\
$(1.06)$ & $(15.9)$ & $(66.7)$ & $(11.2)$ & $(24)$ \\
\hline \hline
\end{tabular}

The transmittance is measured before the deposition of the gold contact.

Table S2: The average PCE parameters obtained for ten solar cells and for the champion device with the configuration ' $\mathrm{FTO} / \mathrm{TiO}_{2} / \mathrm{NVC}$-ink/Perovskite/HTM/MoO $(2 \mathrm{~nm}) / \mathrm{Au} / \mathrm{MoO}_{3}(35 \mathrm{~nm})$ (active area is $0.1 \mathrm{~cm}^{2}$ )', under 1 Sun illumination.

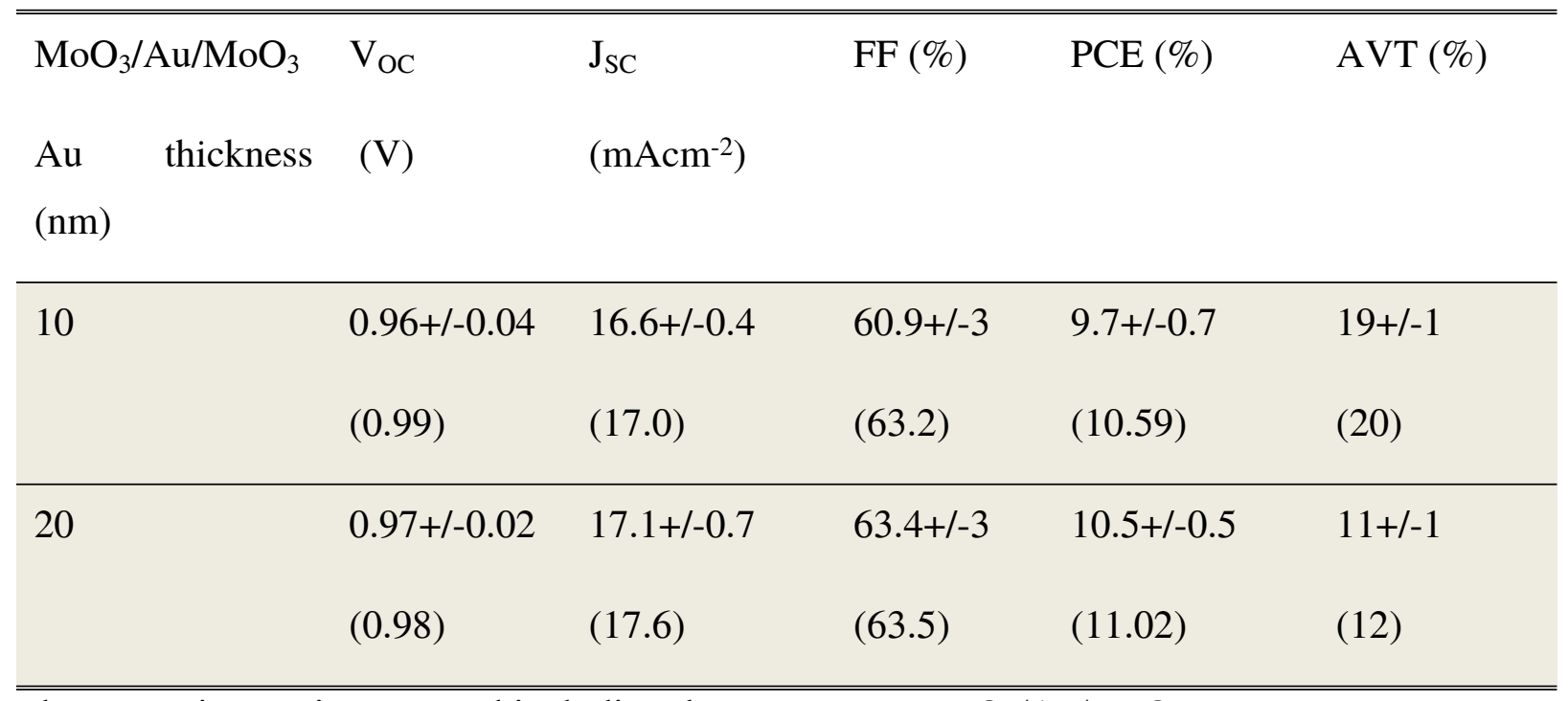

The transmittance is measured including the transparent $\mathrm{MoO}_{3} / \mathrm{Au} / \mathrm{MoO}_{3}$ contact.

Table S3: The miller indices obtained from the selected area electron diffraction (SAED) patterns, during the HR-TEM measurement.

\begin{tabular}{|l|l|l|l|l|}
\hline & 2d-spacing $(\AA)$ & $\mathrm{h}$ & $\mathrm{k}$ & 1 \\
\hline Cs-rich & 9.04 & 1 & 0 & 1 \\
\hline
\end{tabular}




\begin{tabular}{|l|l|l|l|l|}
\hline & 5.25 & 2 & 0 & 0 \\
\cline { 2 - 5 } & 9.1 & 1 & 0 & -1 \\
\cline { 2 - 5 } & 8.97 & 0 & 0 & -2 \\
\hline \multirow{5}{*}{ Cs-deficient } & 2.0 & 3 & 0 & 0 \\
\cline { 2 - 6 } & 1.329 & 3 & 3 & 2 \\
\cline { 2 - 5 } & 0.99 & 5 & 3 & 2 \\
\cline { 2 - 5 } & 2.1 & 2 & 2 & 0 \\
\hline
\end{tabular}
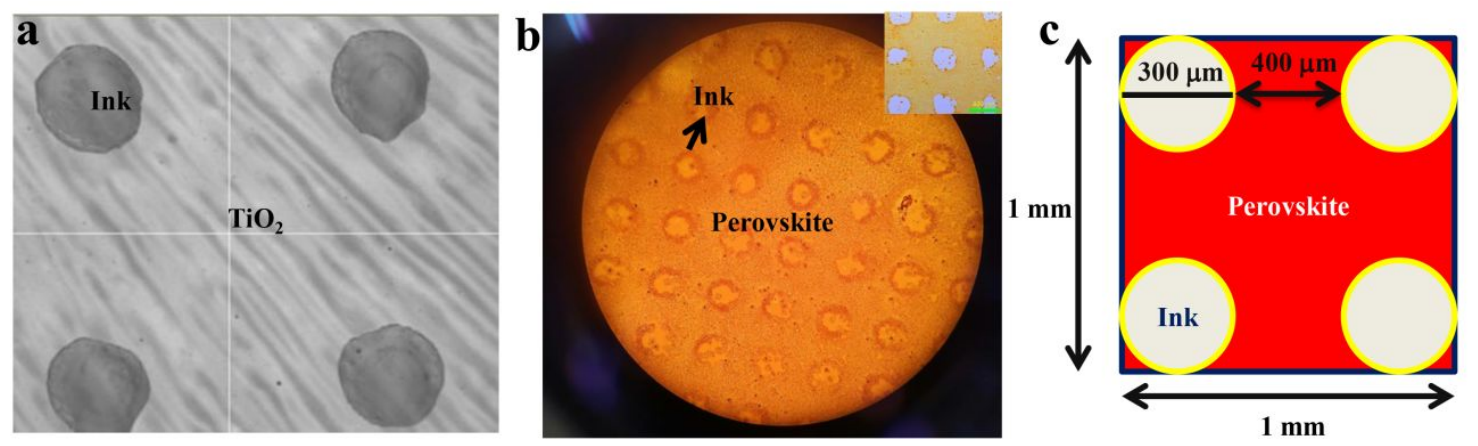

Figure S2: polymerized transparent NVC-ink on $\mathrm{TiO}_{2}$ (a); optical-microscopic image of the NVCink pillar embedded perovskite (b); Scheme represents the number of NVC-ink spots present within the perovskite area of $1 \mathrm{~mm}^{2}(\mathrm{c})$.

From the geometrical model (Figure S2c)

1 pixel on $0.7^{2} \mathrm{~mm}^{2}(0.4 \mathrm{~mm}$ spacing $+0.3 \mathrm{~mm}$ diameter pixel) .

1 pixel with the area of $0.15^{2} \mathrm{~mm}^{2 *} \mathrm{pi}=\sim 0.07 \mathrm{~mm}^{2}$ on an active area "unit cell" of $0.7^{2} \mathrm{~mm}^{2}$. This leads to $\sim 7.5 \mathrm{~mm}^{2}$ "effective" active area.

For the champion device, the measured current density is $\left(\mathrm{J}_{\mathrm{sc}}\right)=15.9 \mathrm{~mA} / \mathrm{cm}^{2}$

Therefore, the current $=15.9 \times 0.088$

$$
=1.399 \mathrm{~mA}
$$


Then, $\mathrm{J}_{\mathrm{sc}}$ for the normalized area $=1.399 / 0.075$

$$
=18.65 \mathrm{~mA} / \mathrm{cm}^{2}
$$

PCE for the normalized area $=(18.65 \times 1.06 \times 66.7) / 100 \%$

$$
=13.18 \%
$$

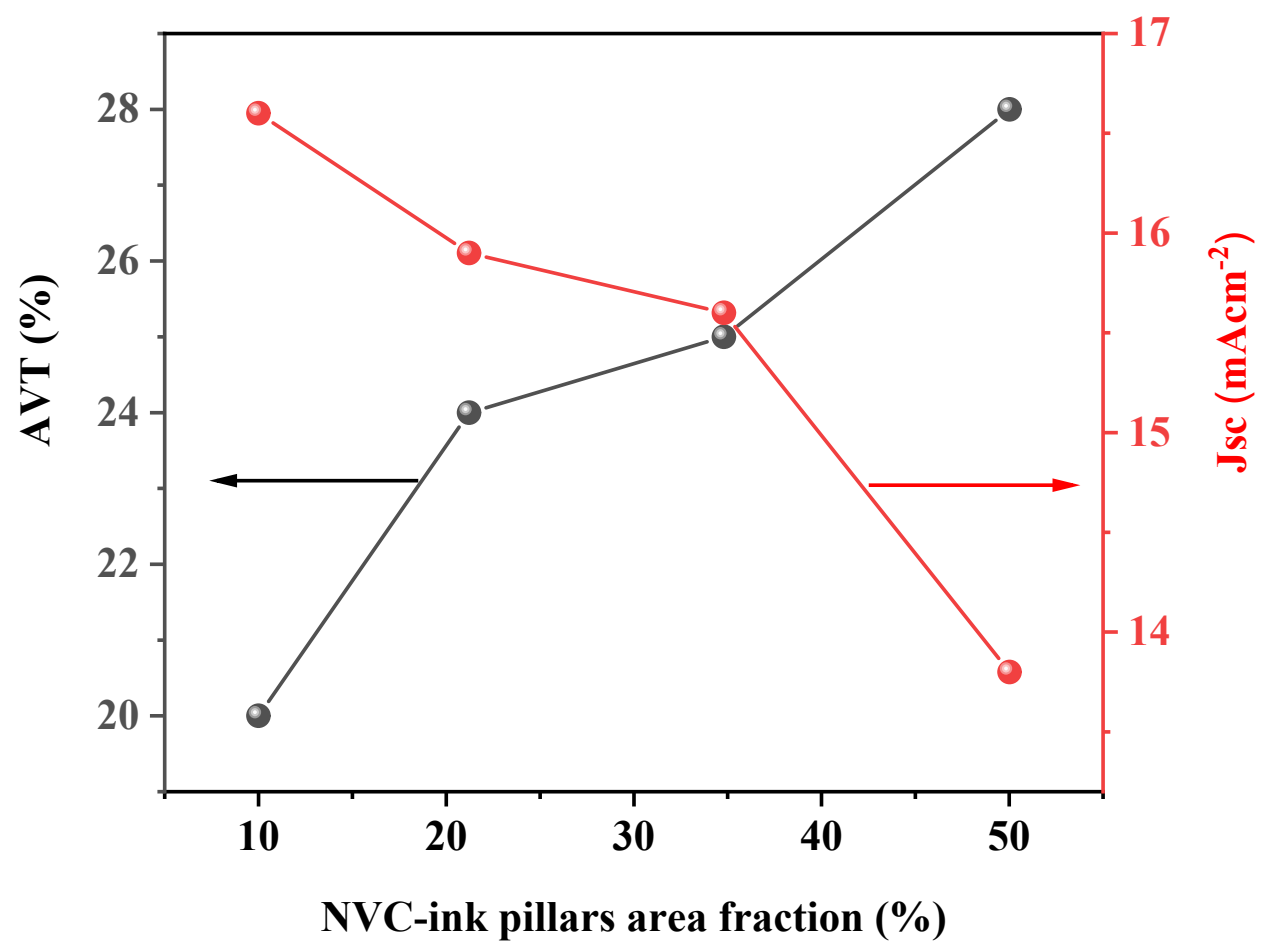

Figure S3: The corresponding AVT and Jsc values measured for the NVC-ink devices versus the overall area of the printed polymer pillars.

Table S4: The experimental $\mathrm{J}_{\mathrm{SC}}, \mathrm{AVT}$ and theoretically calculated AVT values for the NVC-ink

\begin{tabular}{|c|c|c|c|}
\hline $\begin{array}{l}\text { Jsc }\left(\mathrm{mAcm}^{-}\right. \\
2)\end{array}$ & Ink pillar area fraction & Experimental AVT \% & $\begin{array}{l}\text { Theoretical AVT \% } \\
\text { (The reduced Jsc, \%) }\end{array}$ \\
\hline 16.6 & 10 & 20 & 21.7 \\
\hline 15.9 & 21.2 & 24 & 25 \\
\hline 15.6 & 35 & 25 & 27 \\
\hline
\end{tabular}
PSCs. 
The theoretical AVT is calculated as follows

The cell with AVT zero can generate a maximum Jsc $21.1 \mathrm{mAcm}^{-2}$

Therefore for $16.6 \mathrm{mAcm}^{-2}$, the Jsc $\%=(16.6 / 21.1 \times 100)$

The theoretical AVT $=100-78.3$

$$
=78.3 \%
$$

$$
=21.7 \%
$$

Table S5: The PCE parameters obtained for solar cell device with the configuration 'FTO/TiO $/$ /NVC-ink/Perovskite/HTM/Au', under 1 Sun illumination.

\begin{tabular}{lcccc}
\hline Voltage sweep & $\mathrm{V}_{\mathrm{OC}}(\mathrm{V})$ & $\mathrm{J}_{\mathrm{SC}}\left(\mathrm{mAcm}^{-2}\right)$ & $\mathrm{FF}(\%)$ & PCE (\%) \\
\hline Backward & 1.04 & 15.9 & 65.1 & 10.7 \\
\hline Forward & 1.01 & 15.7 & 64.2 & 10.2 \\
\hline \hline
\end{tabular}

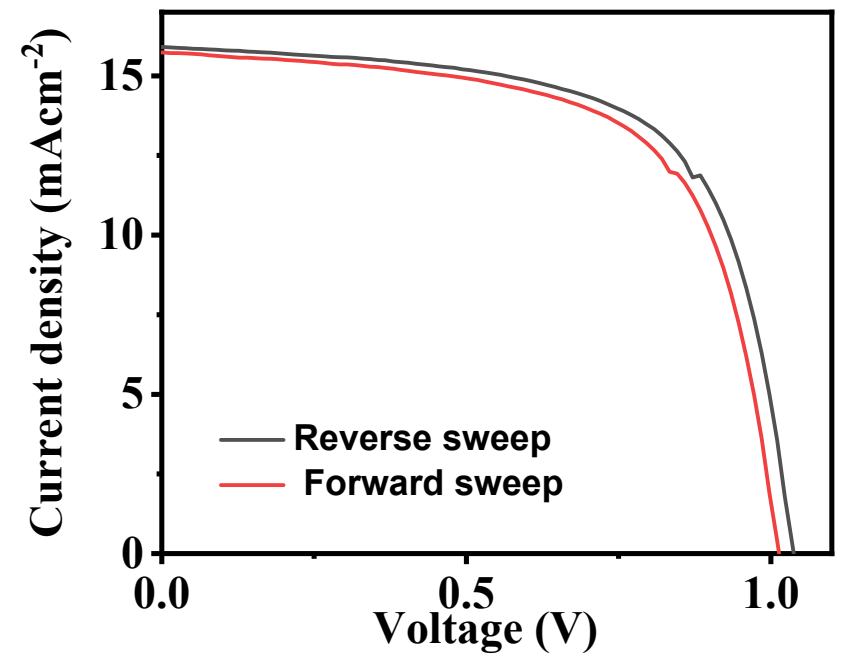

Figure S4: JV curves obtained for the NVC-Ink device. 


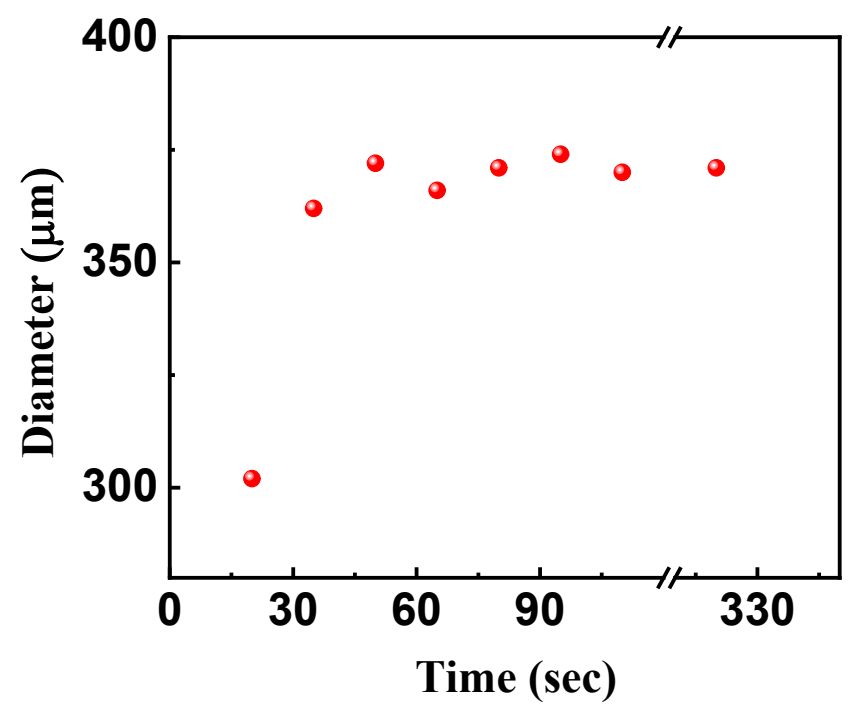

Figure S5: Droplets diameter of printed pillars vs. the waiting time before performing the UV-light curing.

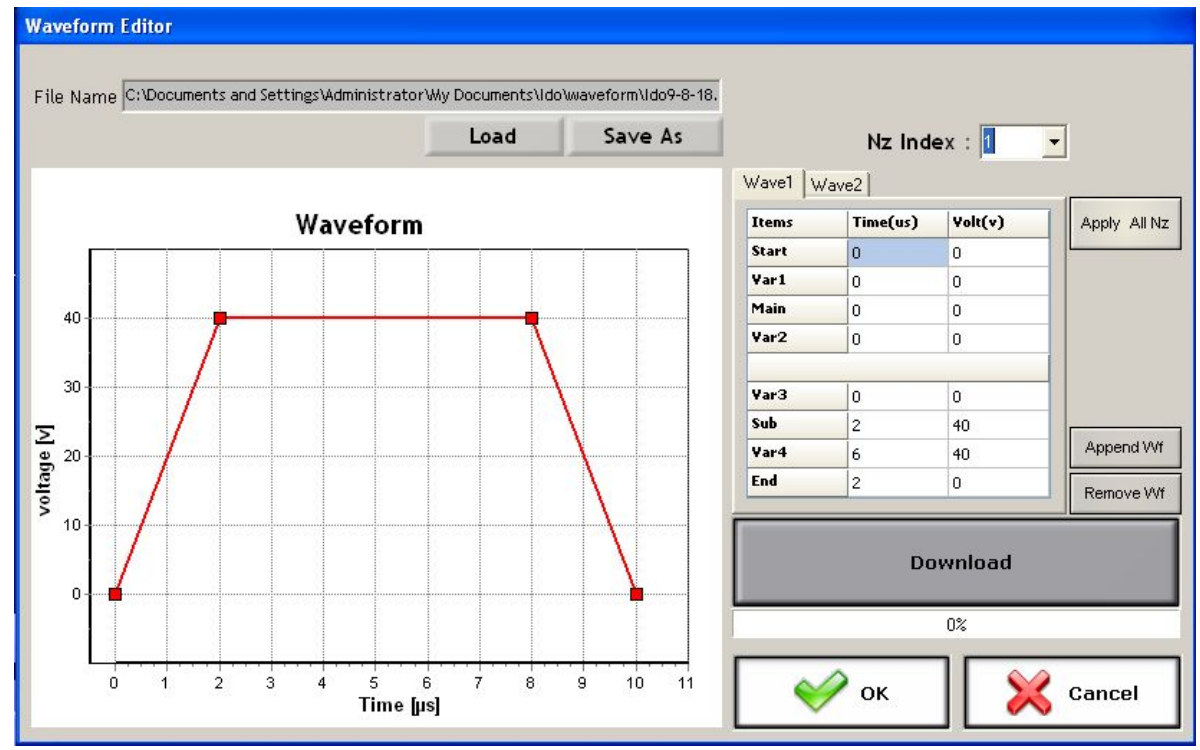

Figure S6: Waveform used for the NVC-ink jetting. 


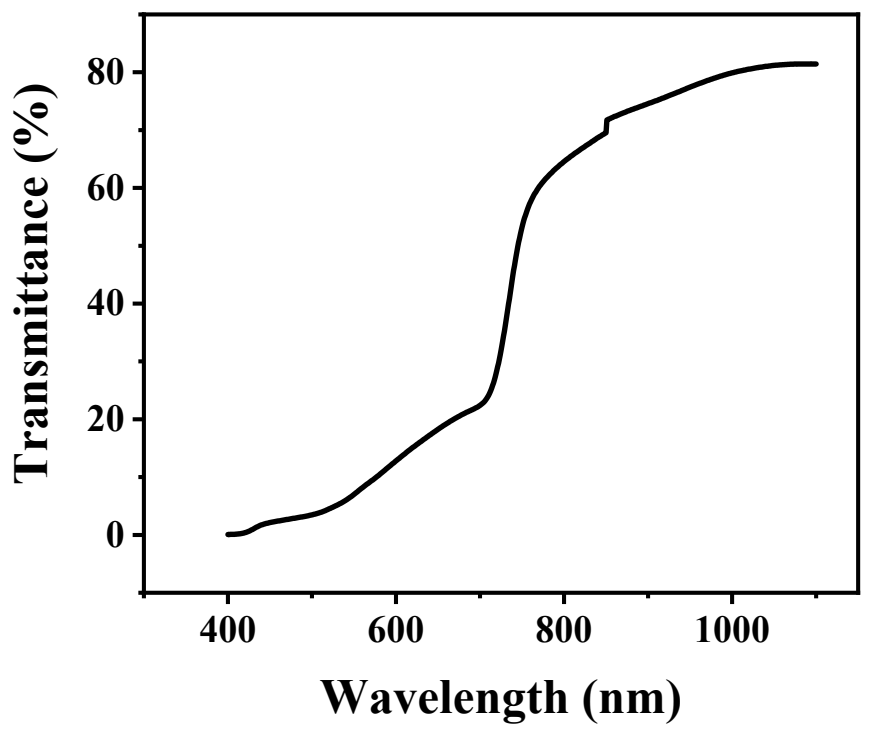

Figure S7: The transmittance plot recorded for the semi-transparent NVC-ink device. 